\title{
'||||||||||||||||||||||||||||||||||||||||||||||||||||||||||||||||||||||.
}

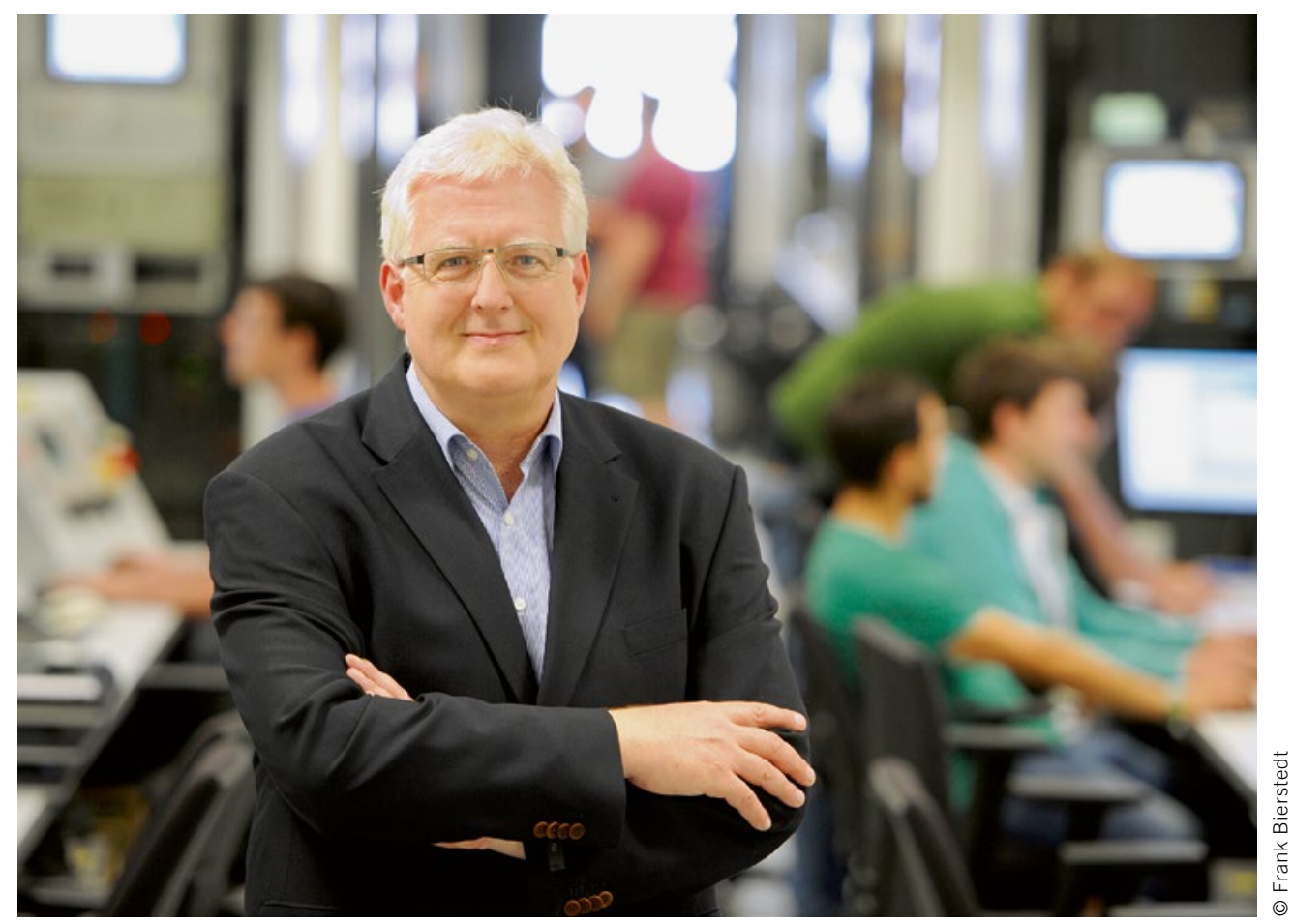

Prof. Dr. Peter Eilts

Director of the Institute of Internal Combustion Engines of the Technical University Braunschweig

\section{LNG as Future Fuel Option}

On the $12^{\text {th }}$ MTZ conference on heavy-duty engines there was a strong focus on large-bore engines, especially for marine application. This industry is facing a radical change because the sulfur content in the fuel will be limited to $0.5 \%$ from 2020 . There are several options to deal with this. The first possibility is low sulfur fuel. This may be distillate fuel or another low sulfur product. It is uncertain in which amount and at what price the latter will be available. The second possibility is the installation of an exhaust scrubber to reduce the emission of sulfur oxide to a level corresponding to a sulfur content of $0.5 \%$ in the fuel. Such a scrubber needs space in the exhaust system, additional tank capacities and energy. Therefore it cannot be retrofitted on all ships.

Another alternative is the use of LNG. In the marine industry mostly dual-fuel engines are used. In most cases they operate with homogeneous charge, so they are otto-cycle engines. As they are run with a lean mixture their efficiency is at least on the level of diesel engines. Furthermore their $\mathrm{NO}_{\mathrm{x}}$ emission is very low, so they fulfil IMO Tier 3 without exhaust aftertreatment.

On the other hand the high cost for the gas system has to be taken into account. Further the infrastructure is not yet available in all harbors. Up to now LNG often was classified as a niche application, e.g. for cruise ships, ferries and of course LNG tankers. But recently large container ships have been ordered which will be operated on LNG. A more widespread application of this fuel can be expected.
The operation of a gas or dual-fuel engine is in some respects not as simple as running a diesel engine. One topic is the knocking propensity of the gas which is of high importance for all engines working along the otto principle. It is characterized by the methane number. Different from the octane and cetane number no standardized measurement procedure exists for the methane number. Instead there are several calculation formulae. Unfortunately these formulae give quite different results in some cases. The methane number of LNG is lower than the one of CNG because of the evaporation of light components. On the other hand the engine manufacturers require a minimum methane number. Therefore a uniform approach is desirable.

A project initiated by the European Association of National Metrology Institutes (EURAMET) is dealing with this issue. In this project the Institute of Internal Combustion Engines of the Technical University Braunschweig is carrying out engine tests to determine the methane number. These will be complemented with reaction kinetic investigations done by the Physikalisch-Technische Bundesanstalt (PTB).

Another issue is low load operation. Because of combustion instabilities dual-fuel engines frequently are switched to diesel operation in this range. The advantages in emissions of LNG operation are lost then. In a project funded by the FVV which we carry out jointly with the Technical University HamburgHarburg we are looking for solutions to this problem. 